\title{
Clinical trial of a chemical test for bacteriuria
}

\author{
LINDSAY PATERSON AND A. W. F. MILLER
}

From the Royal Maternity Hospital, Rottenrow, Glasgow

SYNOPSIS A chemical test for the detection of bacteriuria-Uriglox-has been compared with the results obtained on culturing urine obtained by suprapubic aspiration in 351 pregnant or puerperal women. The results of this comparison show a correlation of $96.9 \%$, both false positive and false negative results occurring.

The demonstration of bacteria in the urine either to confirm a clinical diagnosis of urinary tract infection or as part of a screening programme forms a large part of the work of many bacteriology laboratories. The problem of dealing with large numbers of urine specimens is frequently aggravated by contamination of the specimens and the results are rendered unreliable by the delay occurring between the voiding of the sample and its plating in the laboratory. A test which could detect significant bacteriuria even in a contaminated specimen has been under trial.

The test under consideration is based on the presence of small but detectable amounts of glucose in the urine of healthy persons. In adults the range has been found to vary from 2 to $20 \mathrm{mg}$ per $100 \mathrm{ml}$. In the presence of significant bacteriuria, 100000 organisms per $\mathrm{ml}$ or more, the urinary content of glucose is reduced as a result of multiplication of the organisms. Fritz, Köhler, and Scherstén (1969) demonstrated the reliablity of a reduction in urinary glucose as an indication of urinary tract infection. The Uriglox test strips consist of porous paper, the lower portion of which is impregnated with an ionexchange resin and the upper portion with a sensitive glucose test substance. At physiological levels of $2.0 \mathrm{mg}$ per $100 \mathrm{ml}$ the test strip turns blue, while at lower levels, associated with the presence of glucosemetabolizing bacteria, it remains colourless. The actual sensitivity of the test was confirmed by testing a range of glucose solutions when it was found that glucose levels below $2.0 \mathrm{mg}$ per $100 \mathrm{ml}$ did not affect the strip whereas levels of $2.0 \mathrm{mg}$ per $100 \mathrm{ml}$ and over turned it blue.

\section{Patients and Methods}

Three hundred and fifty-one pregnant or recently Received for publication 14 March 1973. delivered patients were used in this investigation. None had glycosuria. They were asked to empty the bladder before going to bed and were instructed not to eat anything thereafter. They were also asked not to pass urine within four or preferably six hours before the specimen of urine was collected. If there is insufficient time for the glucose to be metabolized by the organisms, false negative results might occur. A fasting specimen was collected in the morning without special precautions and it was tested with Uriglox within two hours. The test strip is inserted into the urine and read after six to 10 minutes. If it remains colourless bacteriuria is diagnosed; if it turns blue the urine is regarded as sterile.

Thereafter the patient was asked to drink freely and later in the same morning a suprapubic aspiration of urine was carried out. This procedure and the bacteriological methods employed in the examination of the urine have been described previously (Paterson, Miller, and Henderson, 1970).

\section{Results}

The results are summarized in the accompanying table. It will be noted from the table that there were six cases where the Uriglox test was negative but the suprapubic aspiration was positive, an incidence of false negative results of $1.7 \%$. Of the six cases, the

\begin{tabular}{lllll}
\hline No. of Patients & & Uriglox Result & \multicolumn{2}{l}{ Urine Culture } \\
\cline { 1 - 1 } & & Sterile & Infected \\
\hline 319 & Negative & 313 & 6 \\
32 & Positive & 5 & 27 \\
\multicolumn{2}{l}{ Total no. of patients 351 } & &
\end{tabular}

Table Results of Uriglox tests compared with culture of urine obtained by suprapubic aspiration 
organism involved in two was Staphylococcus epidermidis. Repeat suprapubic aspiration was carried out 48 hours later in these and the repeat aspirations were sterile. If we accept that contamination of the urine occurred during collection of the first bladder tap specimens the incidence of false negative results falls to $1.1 \%$. Five false positive reactions occurred, an incidence of $1.4 \%$. These patients showed no evidence of urinary tract infection on repeated aspiration.

\section{Discussion}

The frequency with which a diagnosis of urinary tract infection is suspected in clinical practice and the absence of a close relationship between the occurrence of symptoms and the presence of bacteria in the urine, especially in pregnancy (Paterson et al, 1970), leads to the examination by the laboratories of a large number of sterile urines. This inevitably follows also from screening programmes for bacteriuria. Samples submitted for examination are usually midstream specimens and their deficiencies are well known: the risk of contamination, especially in pregnancy or the puerperium, the need for repeated examination, the insistence on early examination or refrigeration until examination can be carried out, and the time of technical staff occupied in the plating of serial dilutions. These difficulties have led ourselves and others to employ suprapubic aspiration to obtain samples (McFadyen and Eykyn, 1968; Paterson et al, 1970)). This procedure, however, is more suited to use in the ward than in the outpatient clinic or in general practice. The general practitioner is at a particular disadvantage both in obtaining a suitable specimen fo: examination and in transporting it to a laboratory within a reasonable time of micturition. For all these reasons the appearance of a reliable chemical test which could separate sterile from infected urine and which could be carried out on a contaminated specimen would be welcome.

Other such tests have been devised and largely discarded, for example, the Greiss test, the reduction of triphenyl tetrazolium chloride (Simmons and Williams, 1962), and the detection of catalase (Braude and Berkowitz, 1961). Dip-slide methods have overcome some of the difficulties, particularly those of the time between voiding and examination of the urine (Arneil, McAllister, and Kay, 1970). However, the result still depends on organismal counts and in this series 10 out of 140 cases gave a doubtful result (counts between $10^{4}$ and $10^{5}$ organism per $\mathrm{ml}$ ).

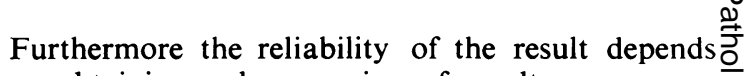
on obtaining a clean specimen for culture.

The Uriglox test appears to be an accurate $\overrightarrow{\overrightarrow{\vec{S}}}$ indication of the presence of multiplying bacteriao and if carried out within a reasonable time of voiding can be used in contaminated specimens. This makes $\overline{\bar{\sigma}}$. it particularly valuable in those situations where it is $\stackrel{\varnothing}{\varrho}$ difficult to obtain a clean specimen for examination, eg, in children, female patients, especially during ${ }_{-}^{\infty}$ pregnancy, and in general practice. The result is? immediately available and only where the test is $\overrightarrow{\vec{\omega}}$ positive need the urine be submitted to bacteriological examination to identify the organism and흥 determine its sensitivity. The accuracy of the test asi determined in this study is similar to that claimed by Kass (1962) for two consecutive midstream speci- $-\omega$ mens obtained under ideal collection circumstances or and with rapid and efficient bacteriological services, 음 that is $96 \%$. The occurrence of false negative results is disappointing, however, as they would limit the 3 value of the test in screening programmes for bacteriuria where only a small number of positives $\overrightarrow{0}$ are likely to be encountered. Emmerson (1972) $\omega$ recorded four apparent false negative results in $1124^{\circ}$ tests but regarded these as unconfirmed after furthero investigation. We have found no explanation for four of the six false negative results in this series and their occurrence requires further investigation.

We thank Dr A. Henderson for bacteriological investigation of the specimens obtained by suprapubic aspiration and for his advice in the preparation of this paper. We are grateful to the nursing staff of the Royal Maternity Hospital for their assistance? and to $\mathrm{Mr}$ J. B. Miller of William R. Warner and Co, Ltd, for supplies of Uriglox.

\section{References}

Arneil, G. C., McAllister, T. A., and Kay P. (1970). Detection of bacteriuria at room-temperature. Lancet, 1, 119-121.

Braude, A. I., and Berkowitz, H. (1961). Detection of urinary catalase $\mathrm{N}$ by disk flotation. J. Lab. clin. Med., 57, 490-494.

Emmerson, A. M. (1972). The use of a simple test for hypoglucosuria (Uriglox) in the diagnosis of bacteriuria in pregnancy. $J . \bigcirc$ Obstet. Gynaec. Brit. Cwlth, 79, 828-832.

Fritz, H., Köhler, L., and Scherstén, B. (1969). Assessment of subnormal urinary glucose as an indicator of bacteriuria in popula $\frac{\sigma}{<}$ tion studies. Acta med. scand., Suppl. 504.

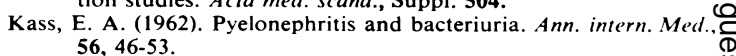

McFadyen, I. R., and Eykyn, S. J. (1968). Suprapubic aspiration of urine in pregnancy. Lancet, 1, 1112-1114.

Paterson, L., Miller, A. W. F., and Henderson, A. (1970). Suprapubic aspiration of urine in the diagnosis of urinary-tract infections during pregnancy. Lancet, 1, 1195-1196.

Simmons, N. A., and Williams, J. D. (1962). A simple test for significant bacteriuria. Lancet, 1, 1377-1378. 